Article

\title{
Study on the Properties of 1319 nm Ultra-High Reflector Deposited by Electron Beam Evaporation Assisted by an Energetic RF Ion Source
}

\author{
Songwen Deng *, Gang Li, Feng Wang, Qipeng Lv, Long Sun and Yuqi Jin \\ Key Laboratory of Chemical Lasers, Dalian Institute of Chemical Physics, Chinese Academy of Sciences, \\ Dalian 116023, China; lig@dicp.ac.cn (G.L.); optics@dicp.ac.cn (F.W.); pepepsi@126.com (Q.L.); \\ sunlong@dicp.ac.cn (L.S.); yqjin@dicp.ac.cn (Y.J.) \\ * Correspondence: buaa_dsw@163.com; Tel.: +86-411-8437-9778; Fax: +86-411-8437-9766
}

Received: 24 December 2017; Accepted: 6 February 2018; Published: 14 February 2018

\begin{abstract}
Ultra-high reflectors, working as a critical optical component, has been widely applied as a cavity mirror in fine optical systems such as laser gyro, F-P interferometer, etc. For decades, ion beam sputtering (IBS) technology, which can deposit ultra-low loss and dense layers, has been commonly believed to be the only and irreplaceable method to fabricate ultra-high reflectors. Thus, reports on other methods are rare and a reflectivity above $99.99 \%$ obtained by evaporation technology (including ion assisted evaporation) has not been seen yet. In the present study, an energetic radio frequency (RF) ion source was introduced during the electron beam evaporation process, which improved the layer quality dramatically. An ultra-high reflector at $1319 \mathrm{~nm}$ with reflectivity of $99.992 \%$ (measured by cavity-ring down method) was successfully deposited on a $\$ 100 \mathrm{~mm} \times 25 \mathrm{~mm}$ single crystal silicon substrate whose surface roughness was approximately $0.420 \mathrm{~nm}$. The surface figure of the reflector was accurately controlled superior to $1 / 6 \lambda(\lambda=632.8 \mathrm{~nm})$. The measured absorption was approximately 3-5 ppm and the calculated scatter based on surface roughness measurement was approximately $6.64 \mathrm{ppm}$. Total loss of the reflector was systematically discussed. This study showed that it is possible to apply electron beam evaporation in ultra-high reflector manufacture and the method is capable of depositing reflectors with an aperture larger than $\$ 600 \mathrm{~mm}$ which is the maximum capacity of current IBS technology.
\end{abstract}

Keywords: electron beam evaporation; ultra-high reflector; ion source

\section{Introduction}

Ultra-high reflector, as a critical component, has been widely applied as a cavity mirror in fine optical systems. To meet the demand of laser gyro industry, ion beam sputtering (IBS) was initially developed to fabricate small $(<25 \mathrm{~mm})$ and ultra-high reflectors in 1970s [1,2]. Driven by strong demands for ultra-high reflectors for cutting-edge optical technology—such as laser interferometer gravitational-wave observatory (LIGO), ring laser gyro (RLG), high-precision laser resonator [3-6], etc.- - lot of research has been carried out on IBS technology ranging from device improvement to deposition process. High reflectors fabricated by IBS can reach total losses below $1 \mathrm{ppm}$ [7] and a reflectivity of $99.99984 \%$ [8]. For decades, IBS technology has been commonly believed to be the only and irreplaceable method to fabricate ultra-high reflectors. Thus, reports on other methods are rare and a reflectivity above $99.99 \%$ obtained by evaporation technology (including ion assisted evaporation) has not been seen yet. Due to the extraordinary properties, the IBS technique has also been tried to fabricate supermirrors with large aperture such as VIRGO mirrors [9]. However, the current IBS technique cannot handle substrates above $\$ 600 \mathrm{~mm}$ due to limitations of ion source technology to the best of our knowledge. 
Electron beam evaporation has always been the most popular method for optical film deposition. Typical application in the frontier of optical technology is the inertial confinement fusion (ICF) laser optics, which are large mirrors $(>1 \mathrm{~m})$, has significantly reduced loss requirements and a high damage threshold [10]. Great effort has been made for the evaporation process to reduce defects and improve the damage threshold [11]. Although ion assisted evaporation (IAE) has made great progress [12,13] in past decades, it was still considered an unsuitable method to deposit ultra-high reflectors due to the porous layer structure or rougher interface compared with IBS technology [14]. Commonly reported reflectivity achieved by ion assisted evaporation is below $99.9 \%[15,16]$.

To explore the possibility of fabricating super mirror with large aperture, the present paper introduced an energetic RF ion source during the electron beam evaporation process to improve the layer quality. A $1319 \mathrm{~nm}$ ultra-high reflector (reflectivity $>99.99 \%$ ) was successfully fabricated. The surface figure was controlled accurately and optical loss of the reflector was measured and analyzed.

\section{Experiments}

\subsection{Sample Preparation}

Figure 1 shows the schema of deposition system in present study, which is a traditional electron beam evaporation system (OTFC-1300, Optorun Co., Ltd., Kawagoe-shi, Japan), equipped with a three-Mo-grids RF ion source. The substrate, facing downward, was mounted on a spinning planetary holder. An optical thickness monitor and quartz thickness monitor were deployed in the center of the chamber to control the thickness and deposition rate, respectively. Electron beam evaporation sources and an RF ion source were deployed in the bottom of the chamber. Uniformity masks were used below the substrate holder to adjust the layer thickness distribution across the deposition area. After using the mask, uniformity was superior to $\pm 0.1 \%$.

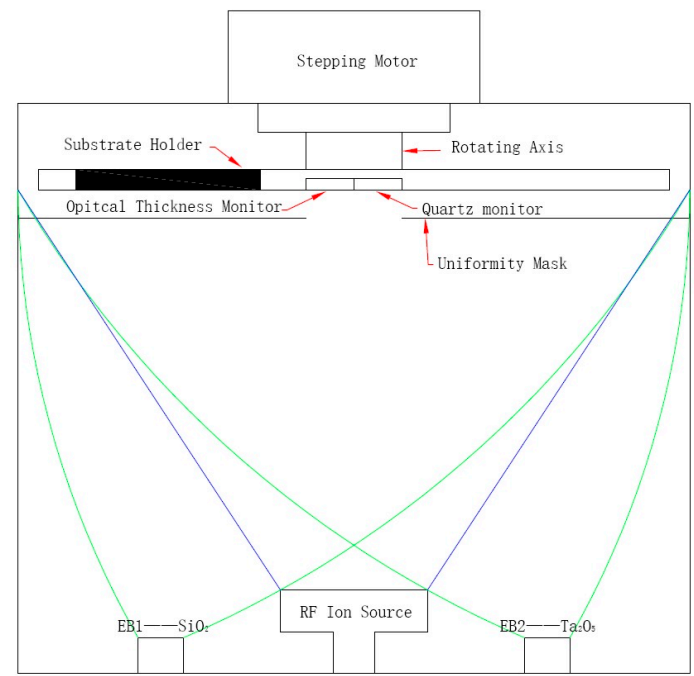

Figure 1. Schema of deposition system.

The layer design of ultra-high reflector was $\mathrm{S}\left|(\mathrm{HL})^{17} \mathrm{H}\right| \mathrm{A}$, where $\mathrm{H}$ denoted high index material $\left(\mathrm{Ta}_{2} \mathrm{O}_{5}\right.$ in present study) with one QWOT (quarter wavelength optical thickness) and L denoted low index material $\left(\mathrm{SiO}_{2}\right.$ in present study) with one QWOT. S denoted substrate and A denoted the incidence medium (air). The theoretical normal-incidence reflectivity of the design is $99.99961 \%$ and the total loss is $3.9 \mathrm{ppm}$, which was calculated by the well-known Matrix method [17]. In the present study, the refractive index was 2.142 and 1.452 for $\mathrm{Ta}_{2} \mathrm{O}_{5}$ and $\mathrm{SiO}_{2}$, respectively. 
A single crystal silicon substrate with diameter $100 \mathrm{~mm}$ and thickness $25 \mathrm{~mm}$ was chosen. The RF ion beam parameters of IAE process were set as: beam voltage $=1100$ and $900 \mathrm{~V}$ for $\mathrm{Ta}_{2} \mathrm{O}_{5}$ and $\mathrm{SiO}_{2}$, respectively; beam current density $=67.8 \mu \mathrm{A} / \mathrm{cm}^{2}$ for both materials. Compared with traditional ion assisted evaporation, the ion energy is much higher in the present study. $\mathrm{O}_{2}$ was used as the working gas of the ion source, which can also adjust the stoichiometry of the layers. The depositing pressure, which was accurately controlled by an auto pressure control system (APC), was set to $1.63 \times 10^{-2} \mathrm{~Pa}$ for $\mathrm{Ta}_{2} \mathrm{O}_{5}$ and $1.45 \times 10^{-2} \mathrm{~Pa}$ for $\mathrm{SiO}_{2}$. The purity of all the working gas was above $99.999 \%$. The deposition rate for $\mathrm{Ta}_{2} \mathrm{O}_{5}$ is $0.3 \mathrm{~nm} / \mathrm{s}$, while $0.6 \mathrm{~nm} / \mathrm{s}$ for $\mathrm{SiO}_{2}$.

\subsection{Property Measurements}

\subsubsection{Measurement of Ultra-High Reflectivity}

Cavity ring-down method is the only and well-known way to measure ultra-high reflectivity. The basic principles and detailed description of the method have been already reported in literature $[18,19]$. The present study used cavity ring-down spectroscopy at $1319 \mathrm{~nm}$ to measure the ultra-reflectivity. Figure 2 gave the schema of the test platform. The incidence angle is $5^{\circ}$. The reflectivity can be calculated by the formula:

$$
R=\mathrm{e}^{\left[\frac{L}{\mathrm{~L}} \times\left(\frac{1}{t_{0}}-\frac{1}{t_{1}}\right)\right]}
$$

where $L$ is the length of the cavity ( $1 \mathrm{~m}$ in our study) and $C$ is the velocity of light. $t_{0}$ and $t_{1}$ the decay time of the ring-down signal in the straight cavity and folding cavity, respectively, which can be obtained by fitting the ring-down signal to the equation:

$$
y=A \times \exp \left(-\frac{x}{t}\right)+B
$$

where $t$ is the decay time.
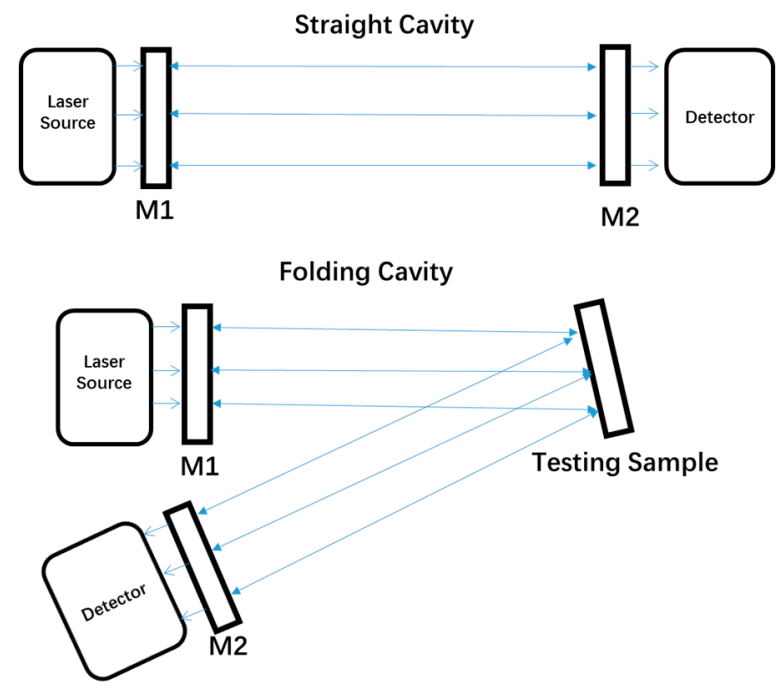

Figure 2. Schema of cavity ring-down spectroscopy.

\subsubsection{Optical Absorption Measurement}

Optical absorption was measured by surface thermal lensing (STL) method [20]. STL is based on creation of phase mismatch between the central and annular portions of the probe beam $(632.8 \mathrm{~nm}$, continuous wave (CW)) which is due to the thermal-optic effect caused by the heat deposit by pump beam $(1319 \mathrm{~nm})$. Figure 3 gives the schema of the measurement setup. Since the self-interference inside the probe beam, a localized perturbation at the chopping frequency occurs at the center of the 
Gaussian profile at one Rayleigh length. The non-perturbed annulus of the probe beam is stripped off with an iris and the perturbed components then detected by the position sensor. The wave front phase difference of the perturbed beam can be measured, from which the absorption can be deduced. The platform was calibrated by using a standard sample, which had absorption of $23 \%$ at $1319 \mathrm{~nm}$. Counting on this platform, absorptions as low as $0.1 \mathrm{ppm}$ could be detected and measured.

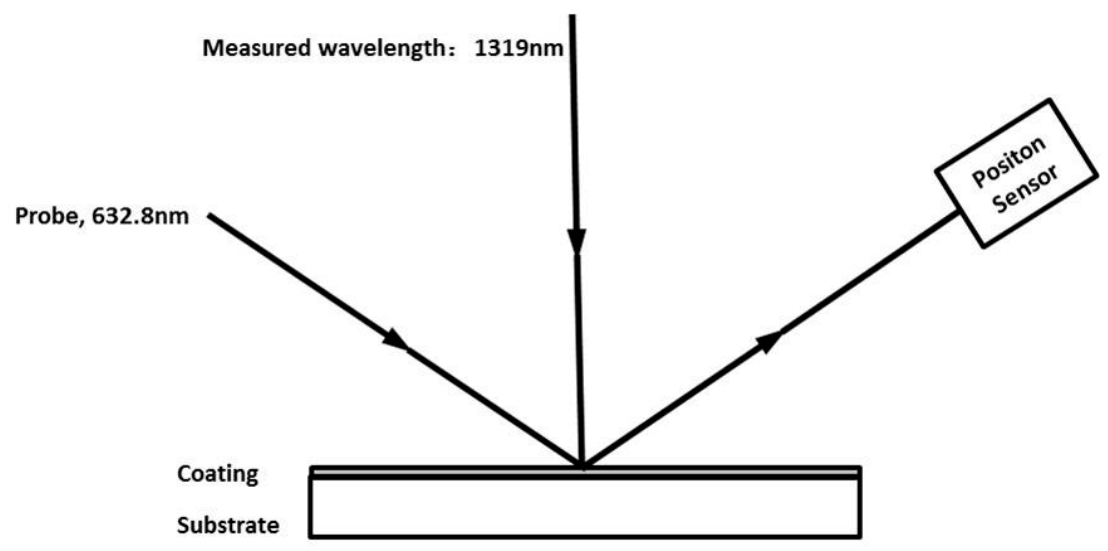

Figure 3. Schema of the low absorption measurement.

\subsubsection{Other Measurement}

Roughness (RMS) was determined in by AFM (Atomic Force Microscope, D3100, Veeco, Plainview, NY, USA). Each sample was scanned in 10 different areas with size of $10 \mu \mathrm{m} \times 10 \mu \mathrm{m}$ and the sample's roughness was determined by the mean value. All the roughness determinations, including substrate and high reflector samples, were carried out in this procedure. The surface figure was measured by interferometer (GPI-XP, Zygo Corporation, Middlefield, CT, USA).

\section{Results and Discussion}

\subsection{Optical Loss Analysis and Reflectivity}

Figure 4 gives the surface profile before and after the reflector deposition measured by AFM. It can be seen that surface roughness decreased from 0.420 to $0.323 \mathrm{~nm}$ after the layer deposition. The coating process exhibited a planarization effect, which was also observed in the IBS deposition coating process [15], while never being reported in the evaporation coating process. This planarization effect can be explained by the classic thin film growth dynamics: if deposited atoms do not have enough energy to migrate on the surface of substrates, the films would have porous microstructure and rough surface. On the contrary, energetic deposited atoms are capable of migrating long distance on the surface of substrates and stop at proper location with lowest surface energy. The films would possess dense microstructure and smoother surface. Present study used the energetic RF ion source to overcome the shortage of low energy electron beam evaporation. Thus, the deposition atoms can obtain enough energy by momentum transfer with the energetic ions.

The scattering of the ultra-high reflector can be analyzed from the surface roughness. Particular roughness with spatial frequencies range from the wavelength of light to the spot size is the direct contributor to scattering. The correlation between roughness and optical scattering is described in the equation [21].

$$
\text { TIS }=32 \pi^{2} n_{0} n_{\mathrm{H}}\left(\frac{n_{\mathrm{H}}-n_{\mathrm{L}}}{n_{\mathrm{H}}+n_{\mathrm{L}}}\right)\left(\frac{\sigma}{\lambda}\right)^{2}
$$

where TIS is total integrated scattering, $\sigma$ is surface roughness, and $\lambda$ is working wavelength. $n_{0}, n_{\mathrm{H}}$, and $n_{\mathrm{L}}$ are refractive index of incidence media, $\mathrm{Ta}_{2} \mathrm{O}_{5}$, and $\mathrm{SiO}_{2}$, respectively. Based on this equation, the total scatter of our ultra-high reflector should be $6.64 \mathrm{ppm}$. 
Figure 5 gives the results of absorption measurement. The measured absorption is approximately 3-5 ppm. This absorption level was much higher than the reported results obtained by IBS and traditional electron beam evaporation [22]. The reason was probably due to the impurities introduced by the energetic ion bombardment [23]. This result was also in accordance with reported conclusions of traditional ion-assisted deposition.

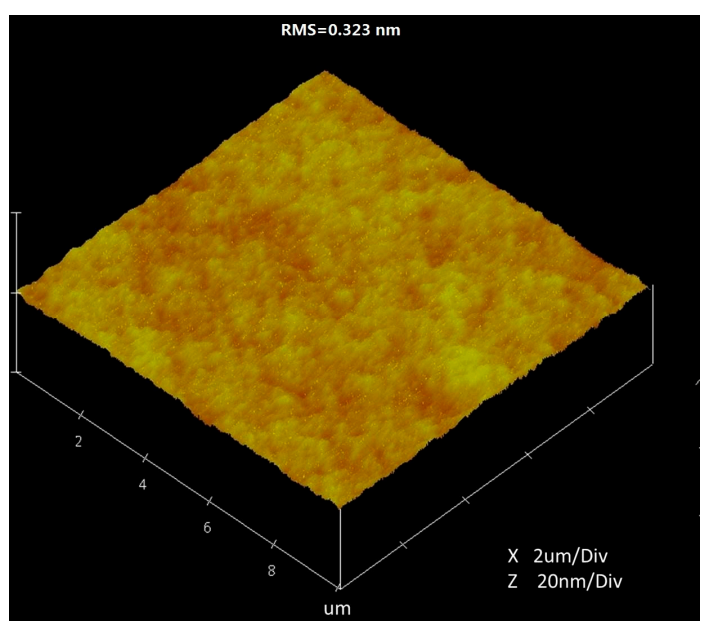

(a)

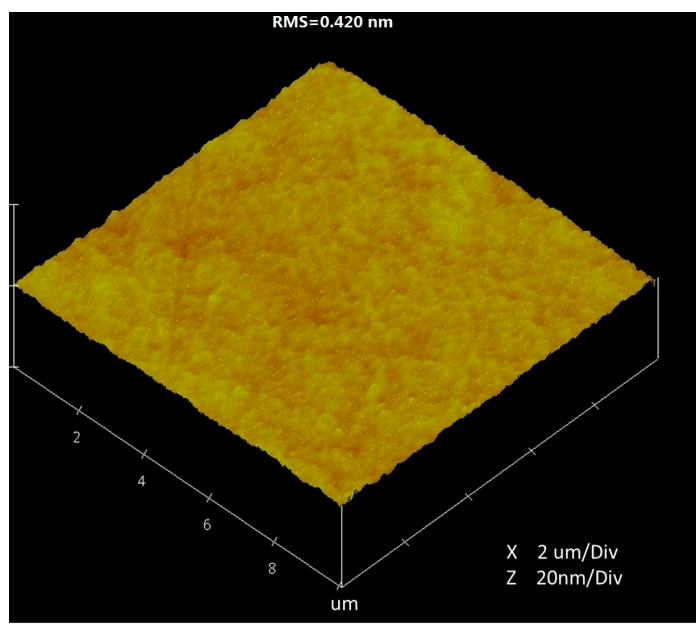

(b)

Figure 4. Surface profile measured by AFM: (a) ultra-high reflector; (b) single crystal silicon substrate.

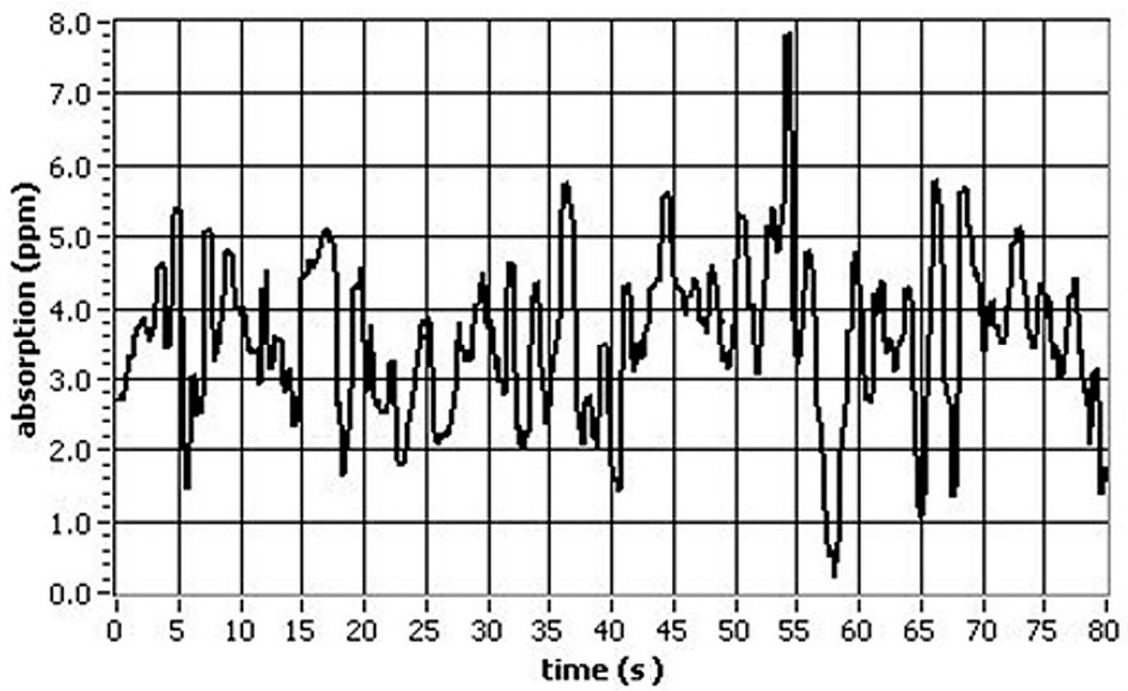

Figure 5. Absorption of the ultra-high reflector.

Figure $6 \mathrm{a}, \mathrm{b}$ shows decay curve of ring-down signals of the straight cavity and folding cavity, respectively. The obtained reflectivity was $99.992 \%$, which is the highest reported reflectivity achieved by electron beam evaporation. According to the measured reflectivity, the total loss of our ultra-high reflectivity is $80 \mathrm{ppm}$. However, the total loss (scatter and absorption) based on absorption measurement and scatter calculation should be below $11.64 \mathrm{ppm}$, which is much lower than actual loss. The reasons of this phenomenon are probably due to the scatter: (1) the interface of multilayer was rougher than surface according to the planarization effect discussed above; (2) scattering did not only happen in the interface, but also in the layer due to defects of layer microstructure, which was ignored in above analysis. Thus, the actual value of scatter would be much larger than $6.64 \mathrm{ppm}$. Limited by our experiment condition, the scattering cannot be directly measured. Compared with the 
surface roughness of substrate applied in ring laser gyroscopes (below $0.1 \mathrm{~nm}$ ), the substrate used in the present study was much rougher. Thus, it can be predicted that our reflectivity would be much higher if ultra-smoothing substrate was available for us.

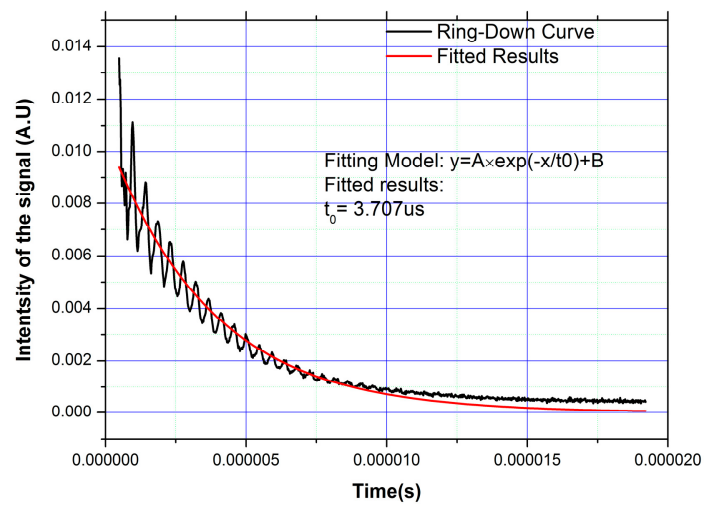

(a)

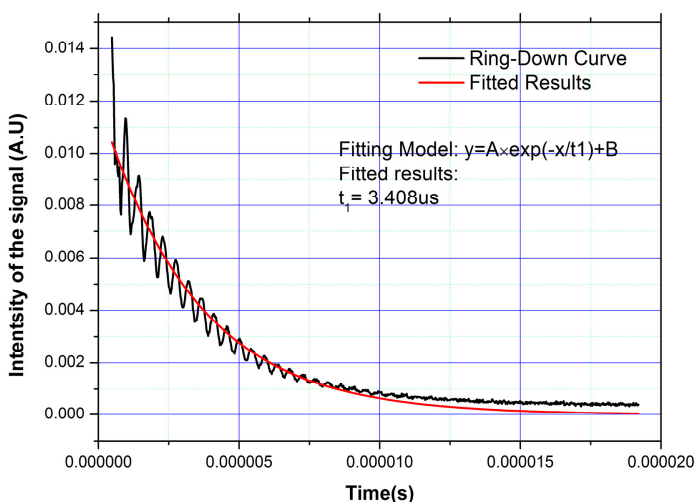

(b)

Figure 6. Decay curve of ring-down signal: (a) straight cavity; (b) folding cavity.

\subsection{Surface Figure Control}

Surface figure is the deviation between the theoretical and actual profile of the optical surface, which directly influences the wave front of transmission. The surface figure of the reflector can be modified by the residual stress introduced by the coating deposition.

In the present study, the residual stress was calculated based on the Stoney Equation [24]:

$$
\sigma=\frac{E_{\mathrm{s}} d_{\mathrm{s}}^{2}}{6\left(1-\gamma_{\mathrm{s}}\right) d_{\mathrm{f}}}\left(\frac{1}{R_{1}}-\frac{1}{R_{2}}\right)
$$

$\sigma$ is the residual stress of the coating. $E_{\mathrm{s}}$ and $\gamma_{\mathrm{s}}$ is the elastic modulus and Poisson ratio of the substrate, respectively. $d_{\mathrm{f}}$ is the thickness of the film. $R_{1}$ and $R_{2}$ are the radius of curvature before and after the coating. $d_{\mathrm{s}}$ is the thickness of substrate. Figure 7 shows the schema of substrate surface. $D$ is the diameter of the substrate. Since the $\theta$ is small enough due to the flat surface. The following equation can be deduced from the geometry:

$$
\begin{gathered}
D \approx 1=2 R \theta \\
P V=h=R(1-\cos \theta)=2 R \sin ^{2}\left(\frac{\theta}{2}\right) \approx \frac{D^{2}}{8 R}
\end{gathered}
$$

The power value change $(\triangle P V)$ which can be measured by ZYGO interferometer meets the equation:

$$
\triangle P V=P V_{1}-P V_{2}=\frac{D^{2}}{8}\left(\frac{1}{R_{1}}-\frac{1}{R_{2}}\right)
$$

Thus, the Stoney equation can be written as:

$$
\sigma=\frac{4 E_{\mathrm{s}} d_{\mathrm{s}}^{2}}{3\left(1-\gamma_{\mathrm{s}}\right) D^{2}} \frac{\Delta P V}{d_{\mathrm{f}}}
$$

For single crystal silicon substrate, $E_{\mathrm{s}}=130 \mathrm{GPa}$ and $\gamma_{\mathrm{s}}=0.23$ were used in the calculation. The diameter of the substrate is $100 \mathrm{~mm}$ while the thickness is $25 \mathrm{~mm}$. For our study, $d_{\mathrm{f}}=6477 \mathrm{~nm}$. $\triangle P V$ is the power value change which can be measured by ZYGO interferometer in the present study.

Figure $8 \mathrm{a}, \mathrm{b}$ showed the surface figure of the substrates and post-deposited ultra-high reflector, respectively. The power value of the surface changed from $0.105 \lambda$ to $-0.224 \lambda(\lambda=632.8 \mathrm{~nm}$ ). The multilayer exhibited compressive stress and the value is $452 \mathrm{MPa}$, which was fairly high. 
To compensate the surface figure change, $\mathrm{SiO}_{2}$ single layer were deposited on the backside of the reflector and the surface figure was controlled superior to $1 / 6 \lambda(\lambda=632.8 \mathrm{~nm})$. Figure $8 \mathrm{c}$ was the final surface figure of the ultra-high reflector.

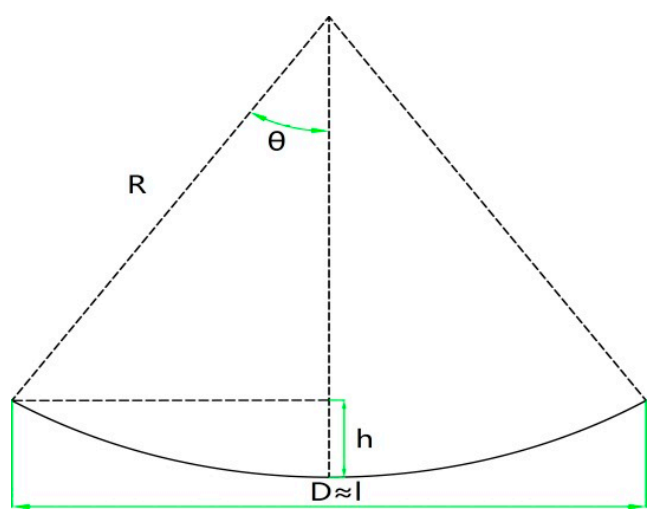

Figure 7. Schema of substrate surface.
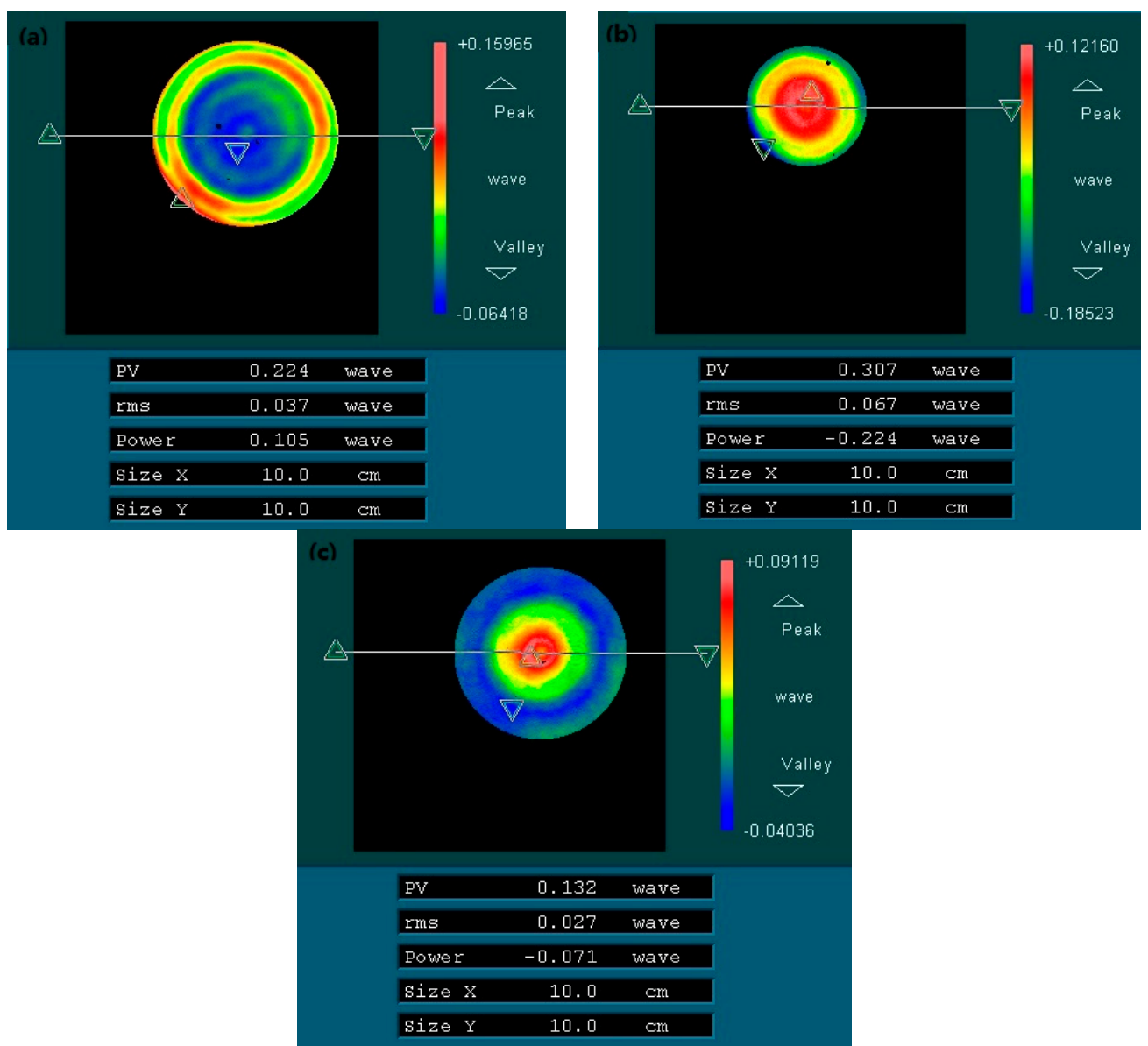

Figure 8. Surface figure measurement: (a) substrate; (b) post-deposited; (c) backside coating compensation.

\section{Conclusions}

An ultra-high reflector at $1319 \mathrm{~nm}$ with a reflectivity of $99.992 \%$ was successfully deposited on single crystal silicon substrate by electron beam evaporation assisted by an energetic RF ion source. To our best knowledge, this was the highest reflectivity obtained by the ion-assisted evaporation 
technology. The absorption of the reflector was below $5 \mathrm{ppm}$ and the main loss was from the scatter. It can be predicted that higher reflectivity can be obtained if a smoother substrate is used, which we will try in our future work. Backside coating was deposited to control the surface figure of the reflector and high accuracy can be achieved. The present study showed that it is possible to apply electron beam evaporation in ultra-high reflector manufacture and the method is capable of depositing reflectors with aperture larger than $\$ 600 \mathrm{~mm}$ which is the maximum capacity of current IBS technology limited by our knowledge.

Author Contributions: Songwen Deng did the literature search, conceived the study design, interpreted the data, and wrote the manuscript. Gang Li participated the study design and data interpretation. Feng Wang and Qipeng Lv collected and analyzed the data. Long Sun and Yuqi Jin participated the study design.

Conflicts of Interest: The authors declare no conflict of interest.

\section{References}

1. Kaufman, H.R. Technology of ion beam sources used in sputtering. J. Vac. Sci. Technol. 1978, 15, 272-276. [CrossRef]

2. Lalezari, R. Low loss ion beam sputtered optical coating and their applications. In Laser-Induced Damage in Optical Materials: 2011, Proceedings of SPIE Laser Damage, Boulder, CO, USA, 18-21 September 2011; Exarhos, G.J., Gruzdev, V.E., Menapace, J.A., Ristau, D., Soileau, M.J., Eds.; SPIE: Bellingham, WA, USA, 2011; p. 819003.

3. Aronowitz, F.; Collins, R.J. Lock-in and intensity-phase interaction in the ring laser. J. Appl. Phys. 1970, 41, 130-141. [CrossRef]

4. Abramovici, A.; Althouse, W.E.; Drever, R.W.; Gursel, Y.; Kawamura, S. LIGO, the laser interferometer gravitational-wave observatory. Science 1992, 256, 325-333. [CrossRef] [PubMed]

5. Gillespie, A.; Rab, F. Thermally excited vibrations of the mirrors of laser in terferometer gravitational-wave detectors. Phys. Rev. D 1995, 52, 577-585. [CrossRef]

6. Thompson, R.J.; Rampe, G.; Kimble, H.J. Observation of normal-mode splitting for an atom in an optical cavity. Phys. Rev. Lett. 1992, 68, 1132-1135. [CrossRef] [PubMed]

7. Jolly, T.W.; Lalezari, R. Ion beam sputter deposition techniques for the production of optical coating of the highest quality. In Thin Films for Optical Systems, Proceedings of Optical Systems Design '92, Berlin, Germany, 1-30 September 1992; Guenther, K.H., Ed.; SPIE: Bellingham, WA, USA, 1993; pp. 250-255.

8. Rempe, G.; Thonpson, R.J.; Kimble, H.J. Measurement of ultra-low losses in an optical interferometer. Opt. Lett. 1992, 17, 363-365. [CrossRef] [PubMed]

9. Forest, D.; Ganau, P.; Lagrange, B.; Mackowski, J.M.; Michel, C.; Montorio, J.L.; Morgado, N.; Pignard, R.; Pinard, L.; Remillieux, A. coatings on large substrates: Towards an improvement of the mechanical and optical performances. Appl. Opt. 2006, 45, 1436-1438.

10. Christopher, J.; Francois, Y.S.; Mark, R.G. Influence of microstructure on laser damage threshold of IBS coatings. In 27th Annual Boulder Damage Symposium: Laser-Induced Damage in Optical Materials: 1995, Proceedings of Laser-Induced Damage in Optical Materials: 1995, Boulder, CO, USA, 30 October-1 November 1995; Bennett, H.E., Guenther, A.H., Kozlowski, M.R., Newnam, B.E., Soileau, M.J., Eds.; SPIE: Bellingham, WA, USA, 1996; pp. 351-360.

11. Sheehana, L.M.; von Gunten, M.K.; Bevis, R.P.; Smith, D.J. The advantages of evaporation of Hafnium in a reactive environment to manufacture high damage threshold multilayer coating by electron-beam deposition. In Advances in Optical Interference Coatings, Proceedings of Optical Systems Design and Production, Berlin, Germany, 26-29 May 1999; Amra, C., Macleod, H.A., Eds.; SPIE: Bellingham, WA, USA, 1999; pp. 318-324.

12. Ehlers, H.; Lappshies, M.; Ristau, D. Ion assisted deposition processes for precision and laser optics. In Advances in Optical Thin Films, Proceedings of Optical Systems Design, St. Etienne, France, 30 September3 October 2003; Amra, C., Kaiser, N., Macleod, H.A., Eds.; SPIE: Bellingham, WA, USA, 2004; pp. 519-528.

13. Ehlers, H.; Becker, K.; Beckmann, R.; Beermann, N.; Brauneck, U.; Fuhrberg, P.; Gaebler, D.; Jakobs, S.; Kaiser, N.; Kennedy, M.; et al. Ion Assisted Deposition Processes: Industrial Network IntIon. In Advances in Optical Thin Films, Proceedings of Optical Systems Design, St. Etienne, France, 30 September-3 October 2003; Amra, C., Kaiser, N., Macleod, H.A., Eds.; SPIE: Bellingham, WA, USA, 2004; pp. 646-656. 
14. Cho, H.-J.; Shin, M.-J.; Lee, J.-C. Effects of substrate and deposition method onto the mirror scattering. Appl. Opt. 2006, 45, 1440-1446. [CrossRef] [PubMed]

15. Stolz, C.J.; Wolfe, J.E.; Mirkarimi, P.B.; Folta, J.A.; Adams, J.J.; Menor, M.G.; Teslich, N.E.; Soufli, R.; Menoni, C.S.; Patel, D. Defect insensitive $100 \mathrm{~J} / \mathrm{cm}^{2}$ multilayer mirror coating process. In Laser-Induced Damage in Optical Materials: 2013, Proceedings of SPIE Laser Damage, Boulder, CO, USA, 23-26 September 2013; Ristau, D., Ed.; SPIE: Bellingham, WA, USA, 2013; p. 888502.

16. Ai, W.; Xiong, S. Investigation of laser-induced damage threshold of hafnia/silica high reflectors at 1064 nm. In Pacific Rim Laser Damage 2011: Optical Materials for High Power Lasers, Proceedings of Pacific Rim Laser Damage Symposium: Optical Materials for High Power Lasers, Shanghai, China, 6-9 November 2011; Shao, J., Ed.; SPIE: Bellingham, WA, USA, 2012; p. 82060G.

17. Macleod, H.A. Basic theory. In Thin-Film Optical Filters; Institute of Physics Publishing: London, UK, 2010; pp. 40-42.

18. Dana, Z.; Anderson, J.C.; Carl, S.M. Mirror reflectometer based on optical cavity decay time. Appl. Opt. 1984, 23, 1238-1245.

19. Virgil, S. High-precision reflectivity measurement technique for low-loss laser mirrors. Appl. Opt. 1977, 16, 1238-1245.

20. Boccara, A.C.; Fournier, D.; Badoz, J. Thermo-optical spectroscopy: Detection by the "mirage effect". Appl. Phys. Lett. 1980, 36, 130-132. [CrossRef]

21. Macleod, H.A. Multilayer high-reflectance coatings. In Thin-Film Optical Filters; Institute of Physics Publishing: London, UK, 2010; pp. 204-208.

22. Stolz, C.J.; Taylor, J.R. Damage threshold study of ion beam sputtered coating for a visible high-repetition laser at LLNL. In 24th Annual Boulder Damage Symposium Proceedings_Laser-Induced Damage in Optical Materials: 1992, Proceedings of Optical Materials For High Power Lasers, Boulder, CO, USA, 28-30 September 1992; Bennett, H.E., Chase, L.L., Guenther, A.H., Newnam, B.E., Soileau, M.J., Eds.; SPIE: Bellingham, WA, USA, 1992; pp. 182-190.

23. Pearson, D.I.; Pochon, S.; Cooke, M. Pearson, Sebastien Pochon, Mike Cooke. Contamination control in ion beam sputter-deposited films. In Nanoengineering: Fabrication, Properties, Optics, and Devices X, Proceedings of SPIE NanoScience + Engineering, San Diego, CA, USA, 25-29 August 2013; Campo, E.M., Dobisz, E.A., Eldada, L.A., Eds.; SPIE: Bellingham, WA, USA, 2004; p. 88161K.

24. Yoon, S.G.; Kim, Y.T.; Kim, H.K. Comparison of residual stress and optical properties in $\mathrm{Ta}_{2} \mathrm{O}_{5}$ thin films deposited by single and dual ion beam puttering. Mater. Sci. Eng. B 2005, 118, 234-237. [CrossRef]

(C) 2018 by the authors. Licensee MDPI, Basel, Switzerland. This article is an open access article distributed under the terms and conditions of the Creative Commons Attribution (CC BY) license (http://creativecommons.org/licenses/by/4.0/). 